\title{
THE REALITY OF THE EVALUATION OF EDUCATIONAL PERFORMANCE IN THE LIGHT OF THE COMPETENCY-BASED APPROACH
}

\author{
Brahim TAMETELT ${ }^{1}$ \\ Asma Ben YAHIA ${ }^{2}$
}

\section{Istanbul / Türkiye \\ p. $605-616$}

Received: $21 / 11 / 2021$

Accepted: 09/12/2021

Published: 01/01/2022

This article has been scanned I iThenticat No plagiarism detected

\begin{abstract}
:
Scientific research endeavors to provide theoretical approaches to various fields and fields, It has been valued by field applications in experimental and descriptive studies on samples planned in several environments, In the pursuit of effective learning through an optimal investment of the learner's environment and its pillars, and by extending the activities of the school outside, from hypothetical problems to real problems of the reality of the learner life. The philosophy of the competency-based approach and its procedures were based on constructive steps to achieve the above, However, she stood on a deep challenge depicted in the assessment, When all the activities are based on the learner's use of his experiences to respond to all the situations he is confronted with, It is therefore a continuous process of evaluation.

practical difficulties, while promoting research with an office approach between the theoretical aspect stipulated in the process and the real environment in which it takes place.
\end{abstract}

Key words: Pedagogical Evaluation, Performance, Efficacity.

http://dx.doi.org/10.47832/2717-8293.15.42

Dr. , Ghardaia University, Algeria, tamehim@gmail.com, https://orcid.org/0000-0003-3485-8155

Researcher. , Ghardaia University, Algeria, soumadz82@ gmail.com, https://orcid.org/0000-0002-6445-1623 


\title{
واقع تقويم الأداء التربوي في ضوء المقاربة بالكفاءات
}

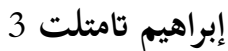 \\ 4 \\ أسماء بن يجيى
}

الملخص:

حرص البحث العلمي على تقديم تناولات نظرية لمختلف المجالات والميادين، ثمّنها بتطبيقات ميدانية في دراسات تجريبية ووصفية على عيّنات مقصودة في بيئات متعددة، سعيا نحو تعلم فعال من خلال استثمارٍ أمثل لبيئة المتعلم

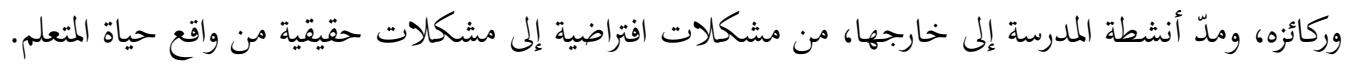

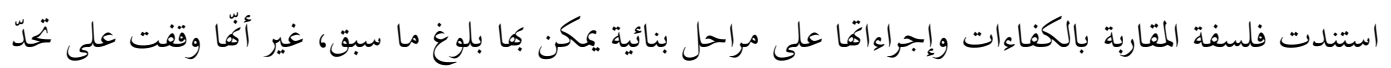

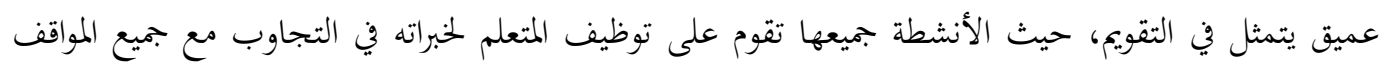
والوضعيات المجاجمة له، من ذلك فهي عملية تقويم مستمرة.

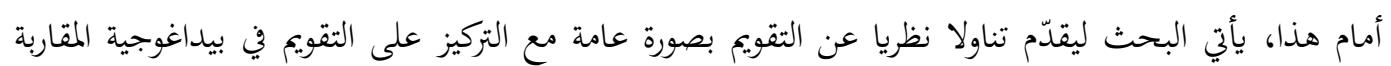

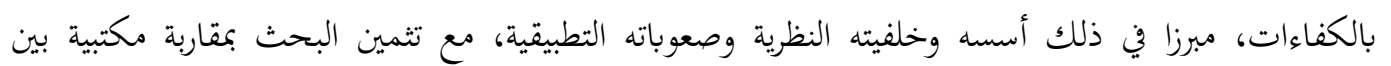
الجانب النظري الذي تنصّ عليه المقاربة والبيئة الفعلية التي تتمّ فيها. الكلمات المفتاحية: التقويم التربوي، الأداء، الكفاءة.

يعدّ التقويم التربوي ركيزة أساسية ضمن ركائز المنظومة التربوية، عليه تُرهن نجاح جميع عمليات التعلم الأخرى، باعتباره عاملا في تشخيص واقع المتعلم للشروع في تحديد مسارات التعلم من جهة وعاملا للوقوف على مستوى مكتسبات التعلم

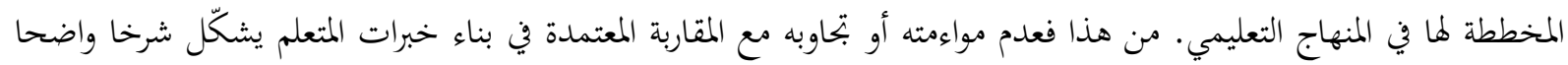

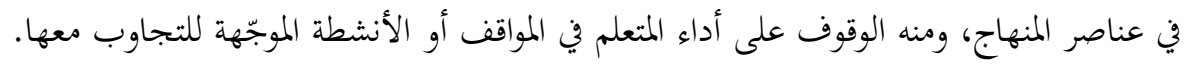

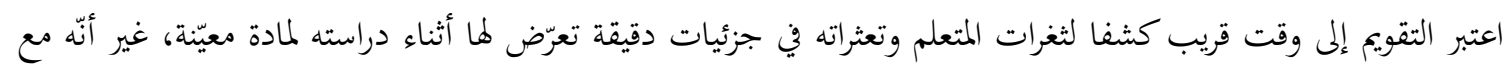

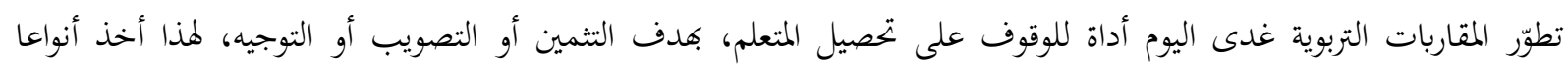
متعدّدة وأشكالا مختلفة، كل منها يستند على أهداف ومعايير محدّدة مسبقا تقف عليها الجهات الوصية، حيث تقوم بمتابعتها والحرص على إجراءاتها الشاملة والجزئية بصورة دقيقة ومستمرة.

فجتت المدرسة الجزائرية سياسات تربوية عدّة من الاستقلال إلى يومنا هذا، واجتهدت في مسايرة المقاربات الحديثة إلى آخرها اليوم والمتمثلة في المقاربة بالكفاءات التي تأخذ بفلسفة التعلم المتمركز على نشاطات المتعلم واستجاباته "مورية المتعلم

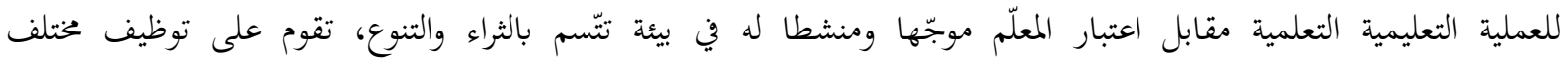

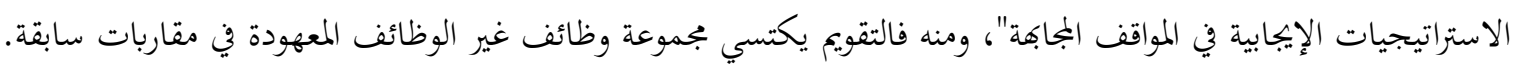


من هذا يعدّ التقويم في بيداغوجية الكفاءات أصعب مرحلة وأعقدها، حيث نالت الكثير من التساؤلات والاستفسارات

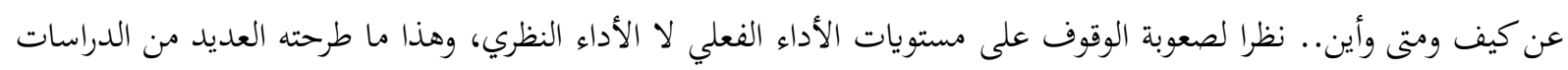

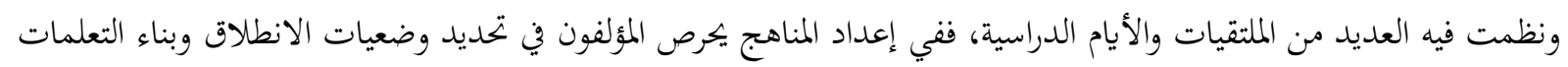

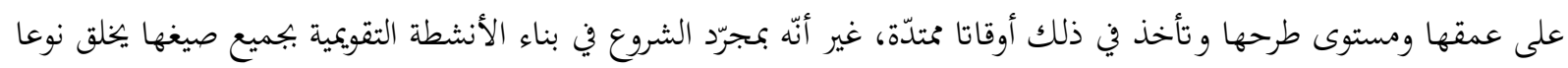

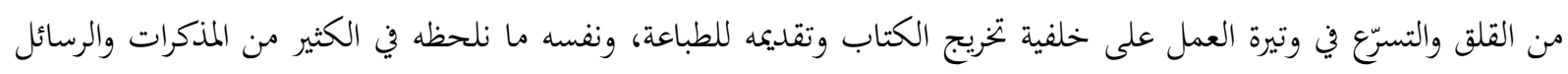

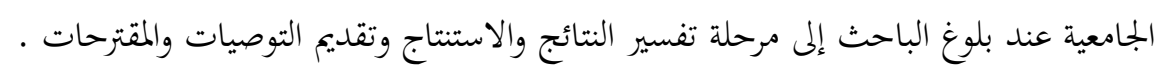
في ملاحظات ووقفات عابرة للباحثين في ميدان التربية والتعليم وقفا على العديد من المعيقات والصعوبات التي يشعر فيها

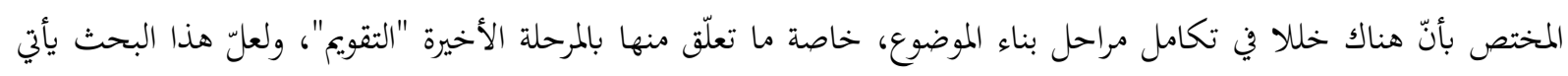

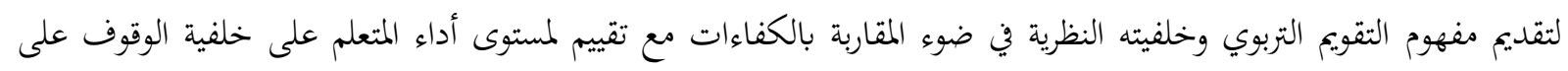
صعوبات المعلم في التقويم، منه يمكن تحديد ذلك في التساؤلات الآتية:

تساؤلات البحث:

1-ما الخلفية النظرية لبيداغوجية المقاربة بالكفاءات؟ وما مفهوم التقويم التربوي في ضوء نفس المقاربة؟

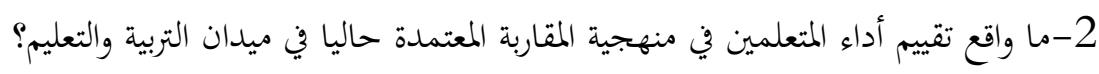

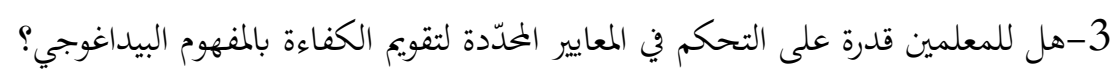

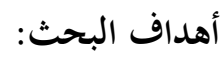

1 2 - تقديم قراءة تراكمية للخلفية النظرية التي قامت عليها المقاربة بالكفاءات.

3 - الوقوف إحصائيا على معيقات التقويم لدى المعلمين في المقاربة بالكفاءات.

4 -إبراز تحديات المقاربة بالكفاءات في ظل ظهور مشكلات تربوية لم تكن موجودة مسبقا.

أهمية البحث:

يأخذ البحث أهميّه في أنه يبحث في موضوع ذا علاقة بتكوين المتعلم، حيث تعدّ بيئة التعلّم شغل جميع السياسات

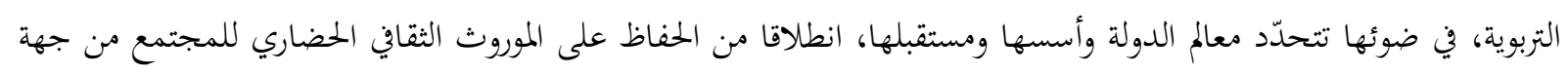

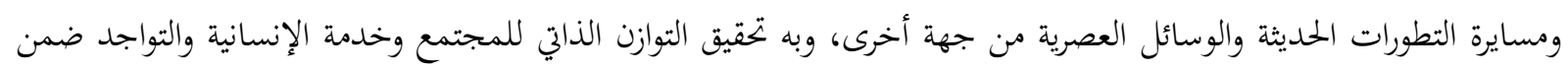

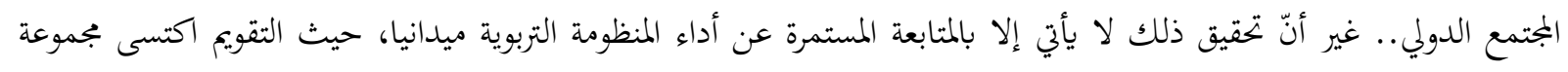

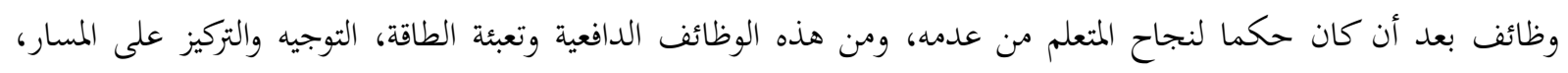
الإرشاد ومراجعة المسار.

وعليه فضعف التقويم في المقاربة المعتمدة يؤدي إلى ضبابية مسار العمل في تحقيق المقاصد والأهداف المنشودة، وانطلاقا

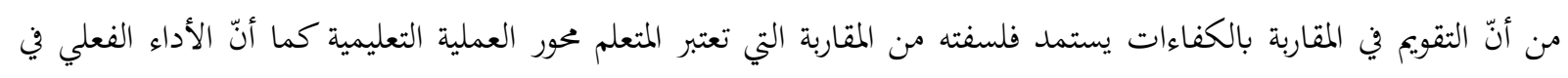

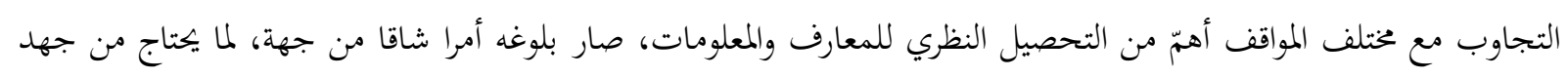

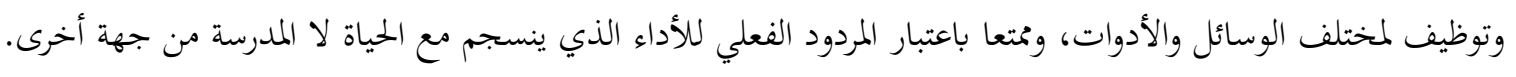


المعايير: "عبارة يستند إليها في الحكم على المهمة في ضوء ما تضمنته العبارة من وصف للسلوك، والممارسات التي تعبر عن قيم أو ابتحاهات أو أنماط تفكير، أو قدرة على حل المشكلات واتخاذ القرارات، باعتبارها خطوطا إرشادية تمثل المستوى النوعي أو الكمي

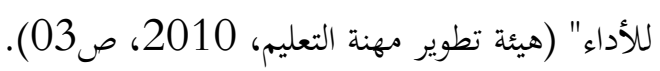

المستويات: تتشابه مع المعايير في أها أسس داخلية للحكم إلا أها تختلف في جانبين، أولمما أها تأخذ الصورة الكيفية وتحدد في

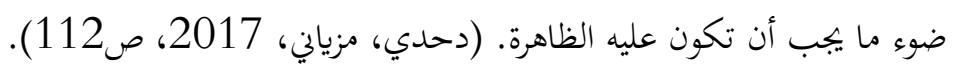
مستويات المعيار: "عبارات تصف السلوك والنشاطات القابلة للملاحظة والقياس، ويمكن تحقيقها والقيام بها، حيث يظهر من

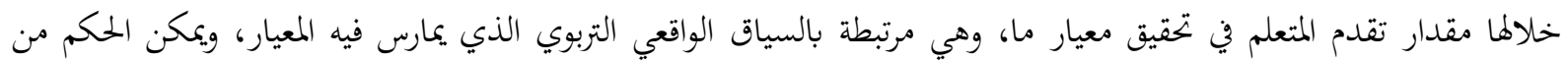

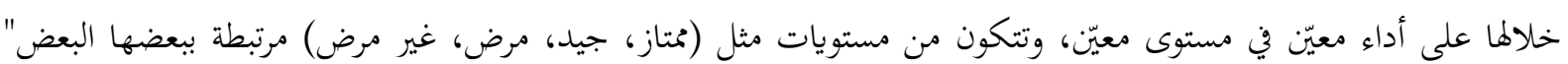

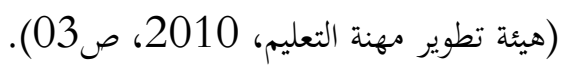

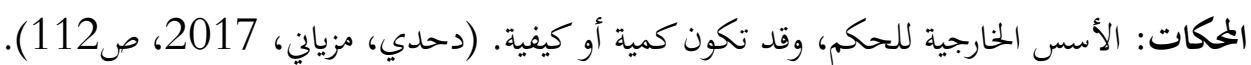
الأداء: ممارسات تطبيقية يقوم بها المتعلم لإنجاز مهام دراسية أو أعباء تنظيمية، أي درجة تحقيق المهام المكونة للوضعيات التعليمية

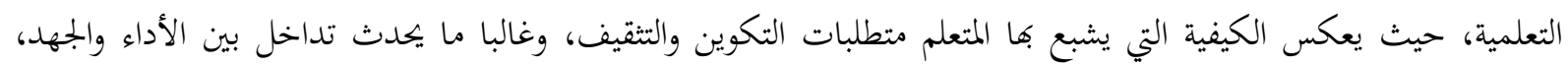

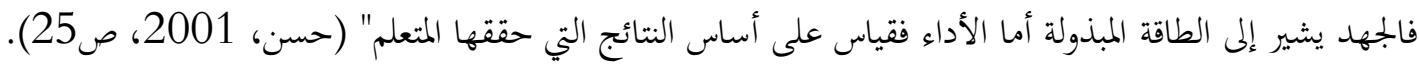
تقويم الأداء: عملية قياس مدى تقدم الفرد في إنجاز المهام الموكلة إليه، في ضوء المعايير والمتطلبات الخاصة بالمجال الذي يشتغل فيه. تقويم أداء المتعلم: عملية قياس مدى تقدم المتعلم في إنجاز وضعيات التعلم المدرسية والمواقف الحياتية الموكلة إليه حسب خصائصه

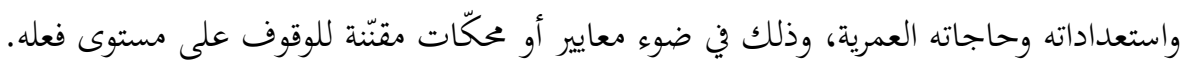
مفهوم التقويم التربوي: صنّف (دحدي، الوناس، 2017، ص117-118) مفهوم التقويم التربوي إلى ثلاثة أصناف، تتمثل في: الصنف الأول: الهدف من التقيم قياس مدى تحقيق الأهداف التربوية مسبقا، منه تعريف بنيامين بلوم "إصدار حكم لغرض ما على قيمة الأفكار والأعمال والحلول والطرق والمواد... يتضمن استخدام المحكات والمستويات والمعايير لتقدير مدى كفاية الأشياء

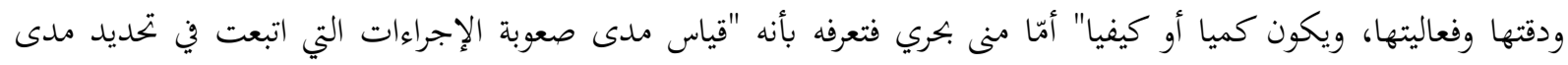

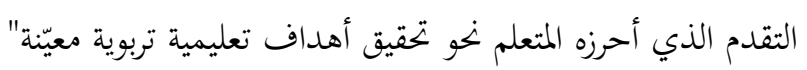

الصنف الثاني: يركز هذا الصنف على الوصف والمقارنة والتحليل والتوضيح كأهداف للتقويم، ومنه تعريف وورثان وسوندارز

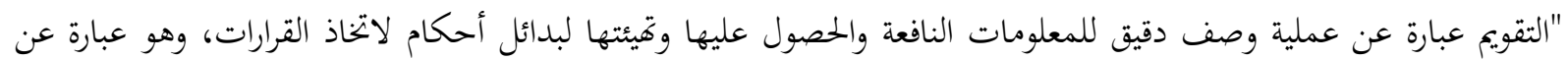

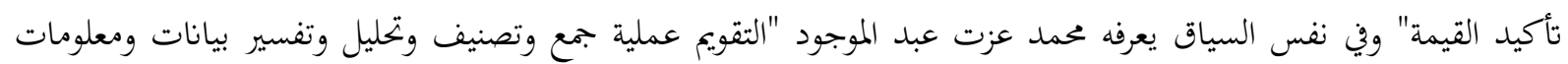
كميا أو كيفيا عن ظاهرة أو موقف أو سلوك بقصد استخدامها في إصدار الحكم أو القرار" الصنف الثالث: يتميز هذا الصنف بتقويم التخطيط لإصدار أحكام جديدة ومراجعة الأساليب الحالية (تغذية راجعة)، في هذا يعرّفه وايلز "التقويم عملية تصدر منها الأحكام تستخدم كأساس للتخطيط، إها عملية تشمل على تجديد الأهداف وتهاف وتوضيح

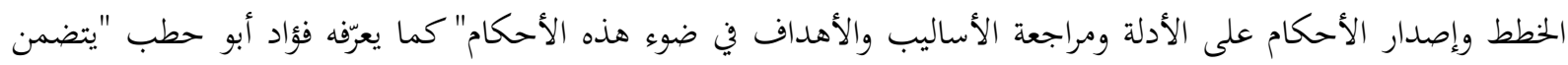
مفهوم التقويم عملية إصدار الحكم على قيمة الأشياء أو الأشخاص أو الموضوعات، وهو بهذا المعنى يتطلب استخدام المعايير أو لورداء 
المستويات أو المكات لتقدير هذه القيمة، كما يتضمن أيضا معنى التحسين أو التعديل او التطوير الذي يعتمد على هذه

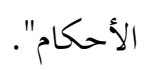

\section{مفهوم التقويم التربوي في المقاربة بالكفاءات:}

يعتبر التقويم التربوي في منهاج المقاربة بالكفاءات عنصرا أساسيا في العملية التعليمية التعلمية يواكبها في جميع مراحلها،

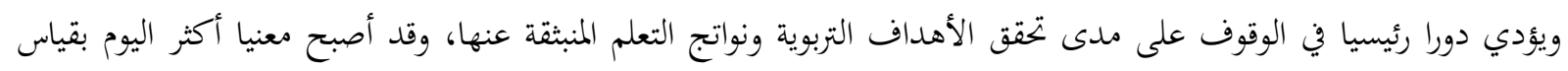

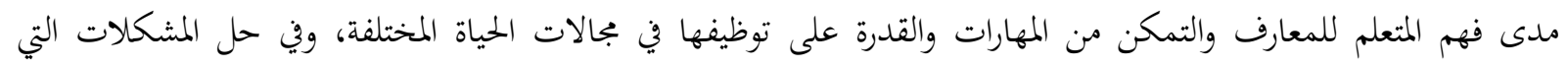
تواجهه، فهو عبارة عن مسعى يرمي إلى إصدار الحكم على مدى تحقيق التعلمات المقصودة ضمن النشاط اليومي للمتعلم بكفاءة ولفي واقتدار.

قدّمت (بوعيشة، بوعمارة، 2011، صادقار 739) مفهوما على أنه "تقويم شيء مركب، لهذا يجب أن يأخذ بعين الاعتبار

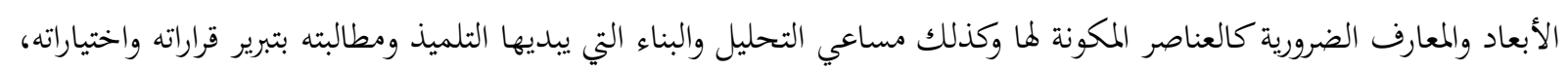

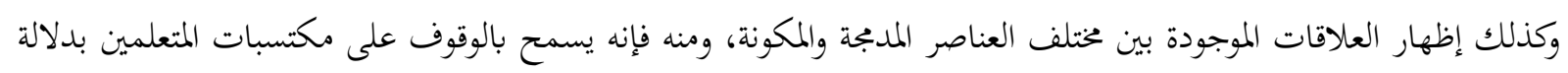

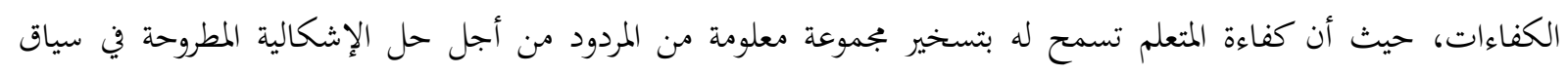
المعلوم".

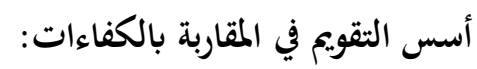

يراعى عند الشروع في تقويم مكتسبات المتعلمين من منطلق المقاربة بالكفاءات، الآتي: (بن سي مسعود، 2008، ص 139) 1- في البداية تحديد الكفاءة بدقة انطلاقا من الوضعية. 2-تبنى وضعية التقويم بشكل ييسر إدماج المعارف الفعلية والمعارف السلوكية والقدرات. 3-وضعية التقويم تكون جديدة على المتعلم. 4-تخضع وضعية التقويم إلى منتوج. 5-تخاطب الوضعية كل تلميذ على حدى. 6- التلميذ فاعل ومشارك.

7-توضع وضعية التقويم في سياق تواصلي وتكون منسجمة مع الكفاءة المستهدفة. 8-ضرورة مراعاة مستوى المتعلمين المستهدفين. 9-تكون وضعية التقويم ذات دلالة بالنسبة للمتعلم. 10-الحرص على الوضوح في تقديم وضعية التقويم وذلك من حيث المقروئية ودقة المعلومات.

الخلفية النظرية لبيداغوجيا المقاربة بالكفاءات: تستند المقاربة على مجموعة نظريات، نركز في هذا البحث على أهم النظريات، والتي تتمثل في:

أ. النظرية البنائية:

إن الأساس الذي نشأت منه المقاربة بالكفاءات هي المدرسة البنائية التي ظهرت كردة فعل عن المدرسة السلوكية التي تحصر التعلم في ( مثير واستجابة )، أما المنظور البنائي فينطلق من أن حصول التأثير يستلزم وجود قابلية في الجسم الذات النيات (المؤثر 
الذات - الاستجابة)، لقد أثرت البنائية على التصورات التعليمية حيث وجه الفعل التربوي نخو وضعيات تفاعلية تثير لدى المتعلم

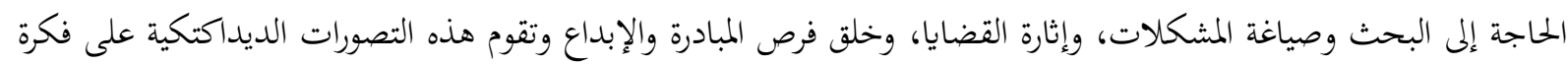

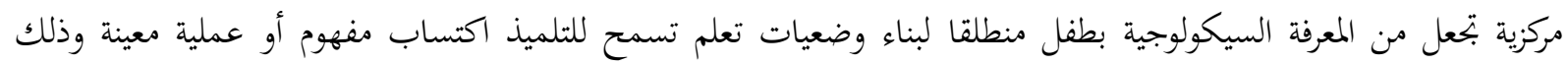

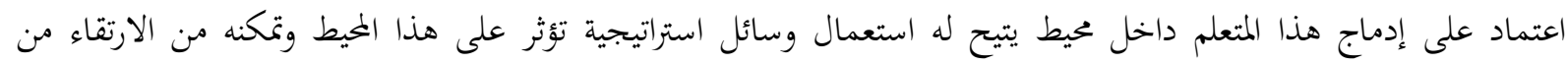

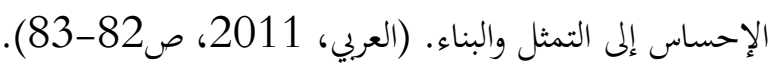

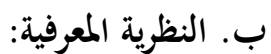

يرى المعرفيون أن السلوك وظيفة للفرد ويؤكدون على البيئة المعرفية لا تتألف فقط من معارف سابقة التعلم ولكنها تتضمن

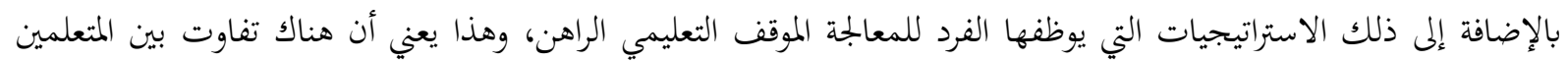
على الرغم من تشابه ظروفهم الخارجية، ذلك أن الاستراتيجيات التي يمتلكوها هي المسئولة عن معالجة الموقف التعليمي الراهن وهذا يعني أن هناك تفاوتا في بنايهم العقلية، وعلى هذا الأساس فان المعرفيون يركزون كثيرا في أي عملية تعليمية على الإمكانيات

الذاتية للمتعلم.

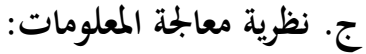

هناك عوامل عديدة أدت إلى ظهور هذه النظرية أهمها الأبحاث المتطورة التي حدثت في بجال الإعلام الآلي، وذلك نظرا للتشابه الكبير بين الحاسوب والذاكرة الإنسانية في معالجة المعلومات، فإذا كان الحاسوب يؤدي وظيفته من خلال ثلاث مراحل وهي: مرحلة إدخال المعلومات، مرحلة المعالجة وتنفيذ البرامج، مرحلة إخراج المعلومات .كذلك الأمر بالنسبة للإنسان فإنه يمر

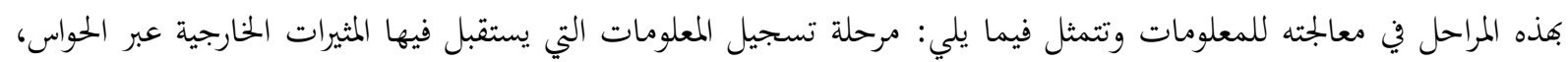

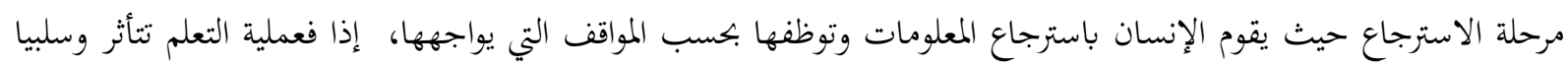

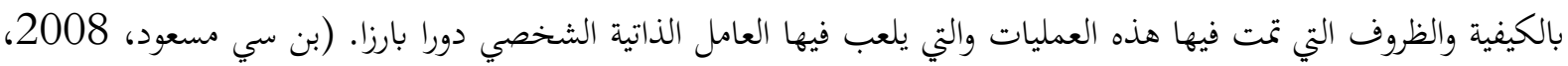
ص(87-86).

وسائل التقويم التربوي:

تتعدّد وسائل التقويم وتتنوع، غير أننا يمكن حصرها في: (رجب، 2001، صنوئم). *** التقويم القائم على الأداء: أي قيام المتعلم بتوضيح تعلمه من خلال توظيف مهاراته في مواقف حياتية حقيقية، او مواقف

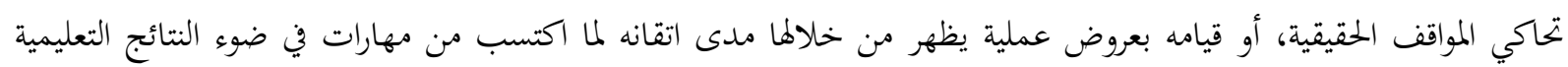
المراد إنجازها. *** ملف الإنجاز (البورتفوليو): تجميع هادف ومنظم لأعمال الطالب وإنجازاته عبر فترة زمنية محددة، ثمّ مراجعتها في ضوء محكات محددة للحكم على مدى تحقيق أدائه لمعايير الجودة المنشودة. 2**** التقويم الذاتي: تقويم المتعلم لنفسه. **قتويم الأقران: قيام كل متعلم بتقييم أعمال أقرانه. *** تقويم الأداء القائم على الملاحظة: عملية يتوجه فيها المعلم بحواسه المختلفة نحو المتعلم، بقصد مراقبته في موقف نشط، وذلك من أجل الحصول على معلومات تفيد في الحكم عليه، وفي تقويم مهاراته وقيمه وسلوكه وأخلاقياته وطريقة تفكيره. *** تقويم الأداء بالمقابلات: لقاء بين المعلم والمتعلم محدد مسبقا، يمنح المعلم فرصة الحصول على معلومات تتعلق بأفكار المتعلم وابتحاهاته نحو موضوع معيّن، وتتضمن سلسلة من الأسئلة المعدة مسبقا. 
*** تقويم الأداء بالاختبارات: الوسيلة التي تستخدم في قياس مدى ما يحققه الفرد ويكتسبه من معلومات وقدرات واتحاهات ومهارات في فاية الخبرة التعليمية. ** تقويم الأداء بخرائط المفاهيم: توجيه المعلم للمتعلم لتحديد المفاهيم المتضمنة في المحتوى عن طريق بناء خريطة مفاهيم، والربط بين هذه المفاهيم. *** دراسة الحالة: كثيرا ما يلاحظ المعلم أن بعضا من تلاميذه يعانون من حالة تأخر عن باقي زملائهم، لهذا يلجأ إلى دراسة

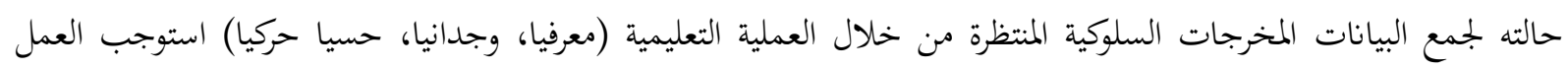

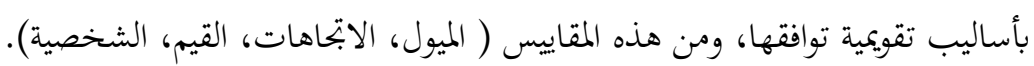
الأسس العامة التي يبنى اللازمة، والمتعلقة بحالثه الأسرية أو المستوى المادي والثقافي لأسرته، وهذا من أجل وضع خطة قصد معالجة

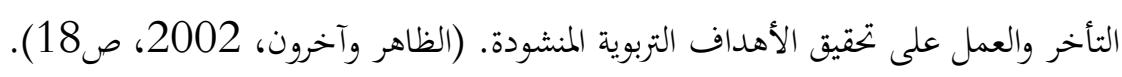
**** المقاييس: تنوع عليها التقويم: يبنى التقويم التربوي على مجموعة من الأسس سواء تعلق ببرنامج أو فرد أو مجموعة أفراد، حيث عدّدها (خوالدة، 2012، ص2012 *** الشمول: يجب أن يكون شاملا للموضوع أو المتعلم، بمعنى أن نُقوّم نمو الطالب في كافة الجوانب العقلية والجسمية والاجتماعية والثقافية. *** الاستمرارية: عملية مستمرة لا تتمّ دفعة واحدة كما هو الحال في بعض الامتحانات التي نحكم من خلالها على المتعلمين نجاحا او رسوبا، لذا ينبغي أن يسير التقويم جنبا مع التعليم من بدايته إلى فهايته. *** التعاون: يجب أن لا ينفرد بالتقيم شخص واحد فقط، فالتقويم عملية يشترك فيها الجميع بما فيها المسؤولين والمعلمين. ** مراعاة الفروق الفردية: يعدّ أساسا جوهريا يجب مراعاته، فليس معنى وجود متعلمين في حجرة دراسية واحدة أفم جميعا

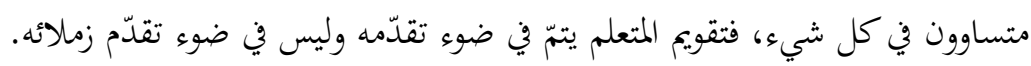
** أن يكون التقويم اقتصاديا: الحرص على الاقتصاد في الوقت والجهد والتكاليف بالنسبة للمعلم والمتعلم. مبادئ المقاربة بالكفاءات: جملها الباحثان (عواريب، الأعور، 2011، ص568) في: أ. الإممالية: بمعنى تحليل عناصر الكفاءة انطلاق من وضعية الشاملة (وضعية معقدة، نظرة عامة، مقاربة شاملة)، ويسمح هذا المبدأ بتحقيق قدرة المتعلم على بتميع مكونات الكفاءة التي تتمثل في السياق والمعرفة. ب. البناء: أي تفعيل المكتسبات القبلية وبناء مكتسبات جديدة وتنظيم المعارف. ج. التناوب: الشامل (الكفاءة)، الأجزاء (المكونات)، الشامل (الكفاءة)، يسمح هذا المبدأ من الانتقال من الكفاءة إلى مكوناها ثم العودة إليها. د. التطبيق: بمعنى التعلم بالتصرف، يسمح هذا المبدأ بممارسة الكفاءة بغرض التحكم فيها. هـ التكرار: أي وضع المعلم عدّة مرات أمام نفس المهام الإدماجية التي تكون في أو مع أو أمام نفس المحتويات، يسمح هذا المبدأ في التدرج بالتعلم. 
و. الإدماج: بمعنى ربط العنصر المدروسة ببعضها، لأنّ إنماء الكفاءة يكون بتوظيف مكونتها بشكل إدماجي إدماجي. ز. التمييز: الوقوف على مكونات الكفاءة من سياق ومعرفة. ح. الملائمة: تكرار وضعيات ذات معنى ومحفزة للمتعلم.

مبادئ التقويم التربوي وفق منهاج المقاربة بالكفاءات: عدّد (حثروبي، 2002، ص298) مبادئ التقويم التربوي في المقاربة

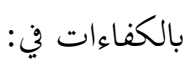

1 1-عدم فصل عملية التقويم عن عملية التعليم والتعلم، بل يجب أن تكون بعدا أساسيا فيها. 2-أن لا يتناول التقويم أساسا المعارف في شكلها الانعزالي، بل هو عملية تمدف إلى الحكم على مدى تحكم المتعلم في كفاءة ما،

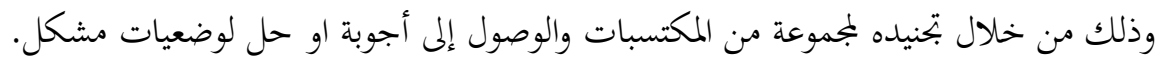

3-إدماج الممارسات التقويمية في المسار التعليمي كمؤشر لإظهار المستوى الذي بلغه المتعلمون، وبالتالي تعديل عملية التعلم. 4-الاعتماد في التقويم التحصيلي خاصة على الوضعيات الإدماجية القريية من الواقع، التي تجعل المتعلم في وعي من ذاته وتمكنه من توظيف مختلف موارده المهارية والمعرفية. 5-تنويع الوضعيات التقويمية التي تثير وتنمي لدى المتعلم مواقف واستراتيجيات مكيفة وفق ما يقتضيه حل المشكلات المطروحة. الفرق بين التقويم التقليدي والتقويم وفق المقاربة بالكفاءات:

\begin{tabular}{|c|c|}
\hline التقويم بمنظور المقاربة بالكفاءات & التقويم بالمنظور التقليدي \\
\hline 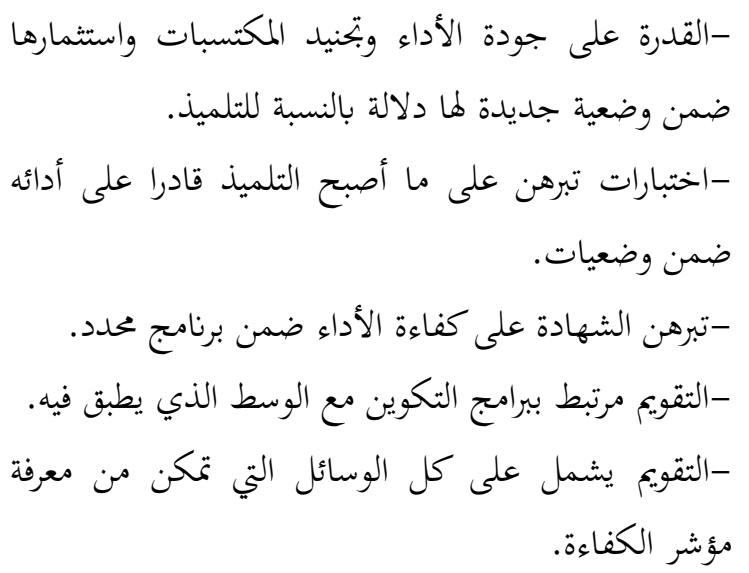 & 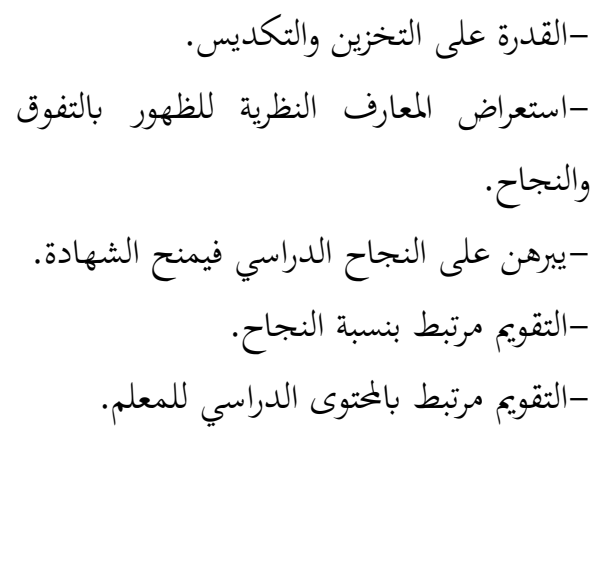 \\
\hline
\end{tabular}

وظائف الاختبار في التقويم بالكفاءات: يتحدّد الاختبار في التقويم بالكفاءات بثلاثة وظائف أساسية تتمثل في الوظيفة

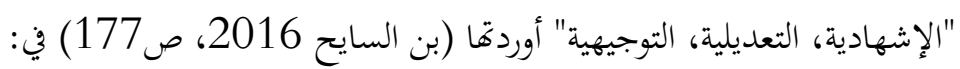

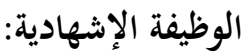

وهي تمدف إلى القيام بكشف شامل للمكتسبات الخاصة بالتعلمات التي من المفروض أها اكتملت، وتبعا لذلك سيسند عدد يتم بمقتضاه الحكم على نجاح التلميذ أو إخفاقه، كما يسمح بتحديد مدى تمّلك التلميذ للمكتسبات المقيّمة من خلاتلال الاختبارات الفصلية (ديسمبر، مارس، ماي)، ومن خلال هذه الاختبارات يتحدّد تملّك التلاميذ لتعلّمات كل فصل، إلاّ أن اختباري الفصلين الأولين يؤديان الوظيفة الثانية للاختبار. 


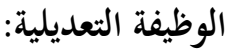

يؤدي الاختبار هذه الوظيفة طالما لم يبلغ التعلم غايته، ومثال ذلك الاختبارات الشهرية في المواد الأساسية (رياضيات، لغة عربية، لغة فرنسية)، حيث يتم اللجوء إلى هذه الاختبارات لتحديد مستوى التلاميذ والقيام بأنشطة علاجية قبل الاختبارات النهائية.

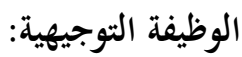

يؤدي الاختبار هذه الوظيفة عندما يتعلق بتقويم المكتسبات القبلية، (قبل بداية التعلّمات) حيث تمدف هذه الوظيفة إلى

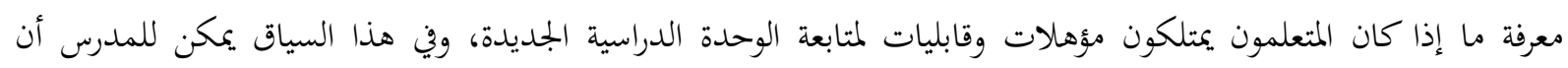
يستعمل اختبارات الاستعداد أو اختبارات تنبئية أو يعطي للمتعلمين تمارين آنية وعاجلة لمعرفة مدى تحكمهم في معارف معينة.

\section{معايير تقويم أداء المتعلم:}

يمكن أن نعتبرها (المعايير)"نظرة نقوم بتسليطها على موضوع أو نشاط خاضع للتقويم" حيث تتضمن أربعة معايير تتمثل في:

$$
\text { الوالاهلامة: الاهناءمة المنتوج للوضعية أي ما قدّمه المتعلم من جواب يعدّ مقبولا للوضعية. }
$$

الاكتمال: صفة الكمال في التناول والوقوف على جدوى اجتماعية للمنتوج مع الإبداع والشعور بالمتعة في الجواب.

صعوبات تقويم الكفاءات ومعيقاتا: ذكرت (بن السايح، 2016، ص207) نقلا عن (بن سي مسعود، 2008، ص140)

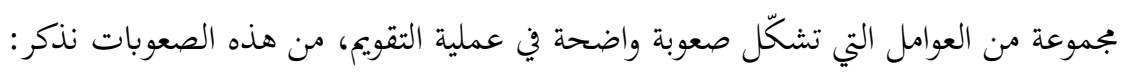
1-كثرة عدد التلاميذ في القسم لا يسمح بتوجيه التقويم نحو القياس وتقدير مدى تطور الكفاءات المستهدفة لدى التلميذ. 2-عدم تكوين المعلمين تكوين جيدا فيما يخص تقويم عمليات تعلم التلاميذ مع عدم إعطاء جانب التقويم الأهمية التي يستحقها.

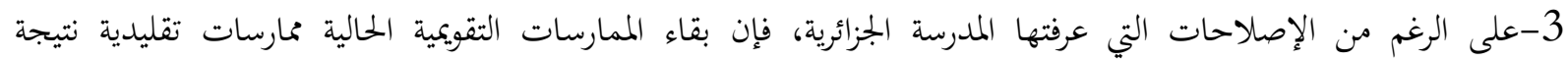
الصعوبات التي يواجهها التقويم بالمقاربة بالكفاءات. في دراسة استكشافية على عيّنة من المعلمين بمنطقة ورقلة للباحثتين (قاجة، بن سكيريفة، 2011) توصلتا إلى أن درجة

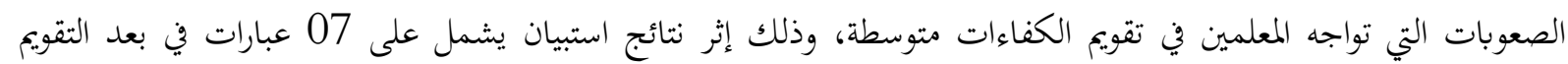

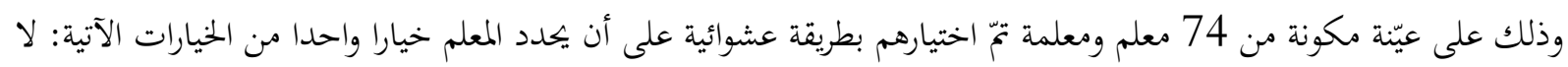
تنطبق (درجة واحدة) تنطبق أحيانا (2 درجتان) تنطبق تماما (3 درجات). علما أن الدراسة شملت ثلاثة أبعاد "التخطيط، مئية

\begin{tabular}{|c|c|c|}
\hline المتوسط الحسابي & 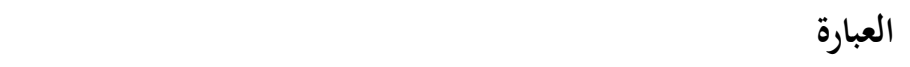 & 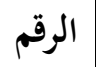 \\
\hline 02.2 & أجد صعوبة في جعل التلاميذ ينجزون كل الأنشطة (التمارين) المقترحة & 1 \\
\hline 01.94 & أجد صعوبة في تسجيل تقدم التلاميذ بصورة منتظمة & 02 \\
\hline
\end{tabular}

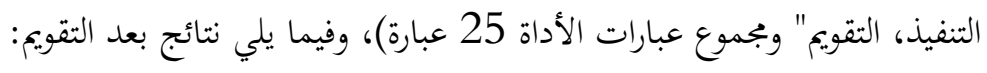

الجدول رقم 01 يوضح المتوسطات الحسابية للصعوبات التي تواجه المعلمين في التدريس في مرحلة التقويم 


\begin{tabular}{|r|r|r|}
\hline 02.09 & $\mathbf{0 3}$ \\
\hline 01.87 & $\mathbf{0}$ & $\mathbf{0 4}$ \\
\hline 02.08 & $\mathbf{1}$ & $\mathbf{0 5}$ \\
\hline 02 & $\mathbf{1}$ & $\mathbf{0 6}$ \\
\hline 01.83 & $\mathbf{0}$ & $\mathbf{0 7}$ \\
\hline
\end{tabular}

جدول رقم 02 يوضح المتوسطات الحسابية للصعوبات التي تواجه المعلمين في التدريس بالكفاءات

\begin{tabular}{|c|c|c|c|}
\hline درجة الصعوبة & المتوسط الحسابي & الصعوبات & الترتيب \\
\hline متوسطة & 01.8028 & مرحلة التخطيط & الثالث \\
\hline متوسطة & 01.8818 & مرحلة التنفيذ & الثاني \\
\hline متوسطة & 01.8857 & مرحلة التقويم & الأول \\
\hline
\end{tabular}

نقرأ في الجدول رقم 01 أنّ المتوسطات الحسابية كانت متوسطة قريبة إلى الارتفاع خاصة ما تعلق بالعبارات (01، 03، 05، 06) حيث نجد أن ضيق الوقت شكل صعوبة أولى في الترتيب تلته صعوبة تحديد الواجبات المنزلية، بعدها تصحيح أنشطة

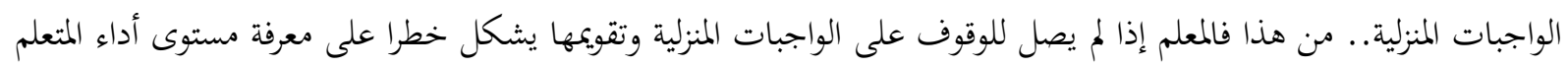

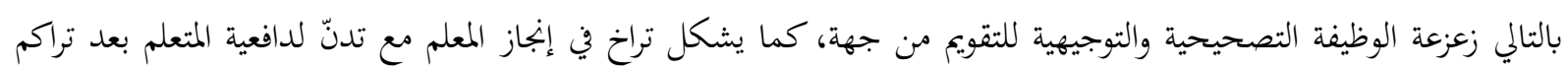

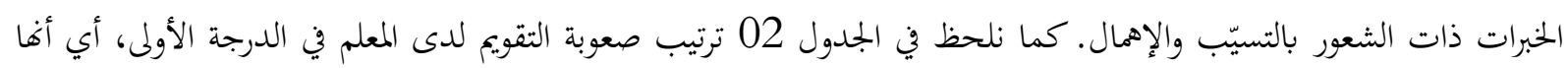
أكثر صعوبة من التخطيط والتنفيذ.

عَزَتِ الباحثتان النتائج إلى ضعف التكوين القاعدي للأساتذة مع الحاجة العميقة للمرافقة البيداغوجية، بدء بفلسفة المقاربة

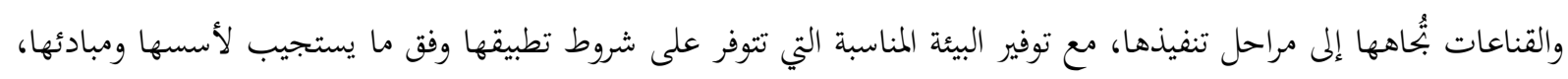

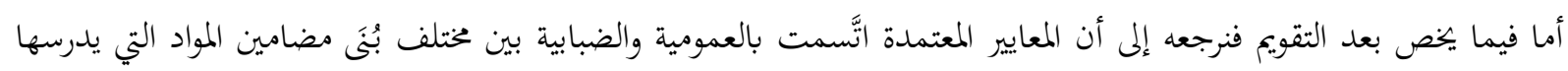

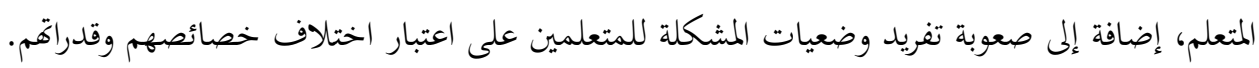

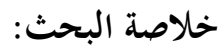

تبنّت المدرسة الجزائرية بعد سلسلة من المقاربات مقاربة الكفاءات، باعتبارها المقاربة التي تدعم المتعلم وتوجّهه في مختلف مواقف التعلّم، حيث هتم بتعليم المتعلم كيف يتعلم وكيف يستجيب مع مواقف حياتية تتشابه مع وضعيات التعلّم للأنشطة المدرسية.

تتطلب بيداغوجية المقاربة بالكفاءات ضوابط ومعايير تفرض توافرها في بيئة المتعلم، بدء بأركان العملية التعليمية إلى مراحل

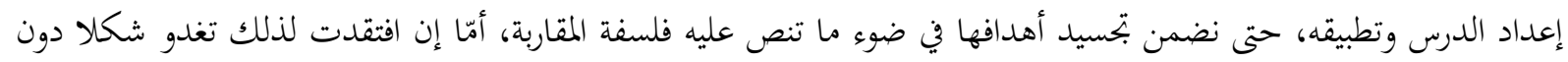
جوهرا، وهذا صلب ما تعانيه في التطبيق الميدان. يحرص التقويم في المقاربة بالكفاءات باعتباره ركنا أساسيا في تحسين العملية التعليمة باستمرار من خلال الرفع من المردودية

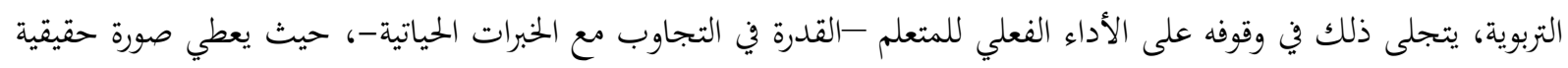
عن مدى تقدم كل متعلّم في تعلّمه. 


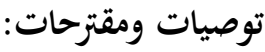

1-تخصيص ميدان التربية والتعليم بأقسام خاصة لمحاكاة التجارب والخبرات الجديدة بهدف نقدها وحوكمتها في ظل ظروف العوامل البيئية والاجتماعية والنفسية للمجتمع قبل الشروع في تعميمها.

2-التركيز على تحقيق الكفاءات المخطط لها في المناهج، على أن تكون السّندات والموارد المدرجة في بناء التعلمات وسائل لا

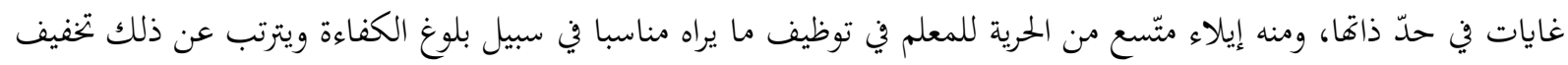
الأعباء الإدراية والتنظيمية.

3-الاهتمام بالتكوين النوعي لمنفذ المقاربة -المعلم-، بدءا بتثمين جهود التكوين والمرافقة المخصصة للأساتذة حاليا ودعمها ببرامج أخرى تخدم مختلف جوانب بيئة المتعلم ومنه مكتسباته المعرفية والمهارية والوجدانية. 4-استثمار بحوث مؤسسات البحث ودراساتا، سواء ما تعلق منها بالمشاريع المتخصصة أو مشاريع فرق المخابر للاستفادة منها

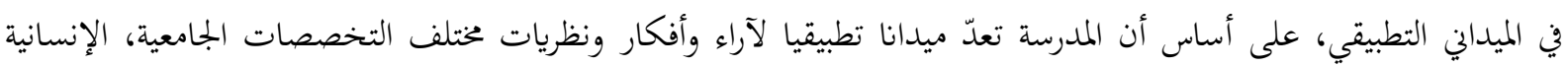
الاجتماعية الأدبية العلمية التقنية والاقتصادية.. 5-إيلاء التقويم التربوي بصفة عامة أهمّية قصوى باعتباره أساس محرّك المنظومة التربوية ونجاحها، ومنه تخصيص موضوع معايير تقويم أداء المتعلم ببحوث ميدانية متخصصة وفي مختلف مجالات المواد التي يدرسها المتعلّم. 
الأخضر عواريب، إسماعيل الأعور (2011)، التقويم في إطار المقاربة بالكفاءات، مجلة العلوم الإنسانية والاجتماعية، المجلد3،

$$
\text { العدد2. }
$$

إسماعيل دحدي، مزياني الوناس (2017)، التقويم التربوي، مفهومه واهميته، مجلة العلوم الإنسانية والاجتماعية، العدد 31، جامعة

$$
\text { قاصدي مرباح. }
$$

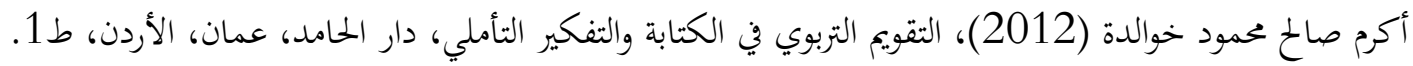
حبّار العالية (2017)، التقويم التربوي في ضوء منهاج المقاربة بالكفاءات، مجلة مقاربات، جامعة الجلفة، المجلد 02، العدد 28.

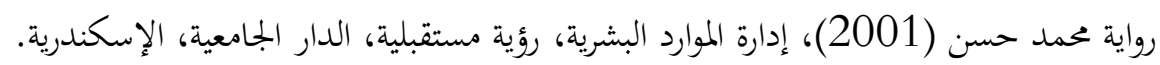
زكرياء محمد الظاهر، تمرجيان جاكلين، جودت عزت عبد الهادي(2002)، مبادئ القياس والتقويم في التربية، الدار العلمية الدولية

$$
\text { ودار الثقافة، ط1، عمان، الأردن. }
$$

كلثوم قاجة، مريم بن سكيريفة (2011)، الصعوبات التي تواجه المعلمين في التدريس بالكفايات، مجلة العلوم الإنسانية والاجتماعية بورقلة، عدد خاص: ملتقى التكوين بالكفايات في التربية: العدد4، جانفي، جامعة قاصدي مرباح

$$
\text { ورقلة، الجزائر. }
$$

لبنى بن سي مسعود (2008)، واقع التقويم في التعليم الابتدائي في ظل المقاربة بالكفاءات، رسالة ماجستير منشورة، كلية العلوم

$$
\text { الاجتماعية، جامعة قسنطينة. }
$$

محمد الصالح حثروبي (2002)، المدخل إلى التدريس بالكفاءات، دار الهدى، الجزائرة فئنة محمود العربي، دراسة كشفية لممارسة المعلمين المقاربة بالكفاءات، رسالة ماجستير منشورة، كلية العلوم الاجتماعية، جامعة وهران، 2011

مسعودة بن السايح (2016)، واقع التقويم في إطار المقاربة بالكفاءات، مجلة العلوم الاجتماعية والإنسانية، جامعة تبسة،

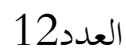

مصطفى رجب (2001)، القياس والتقويم التربوي، وزارة التربية السورية، مديرية الإعداد والتدريب، سوريا.

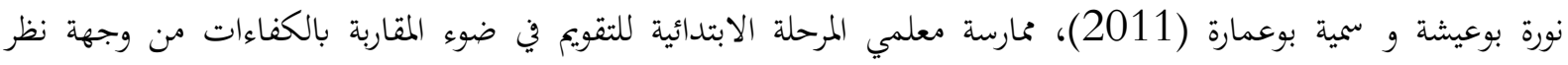
المفتشين التربويين، ملتقى التكوين بالكفايات في التربية، جامعة ورقلة، الجزائر.

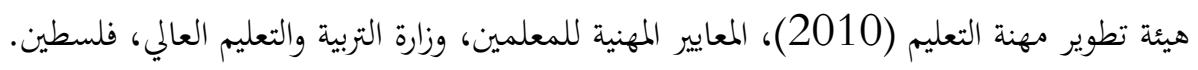

file:///C:/Users/USER/Downloads/37691311.pdf 